\title{
Comment
}

\section{Trabalho e Educação}

\author{
Antonio de Pádua Soares de Sampaio ${ }^{1}$; Iarê Lucas Andrade ${ }^{2}$
}

Resumo: Produzir uma análise acerca do tema trabalho e educação, parte da necessidade de se detectar, sob a ótica da literatura específica, algumas vertentes que auxiliam no processo de entendimento dos elementos que permeiam e embasam a relação trabalho e educação. Objetiva-se com esta análise, elencar indagações pontuais que evidenciam os contextos históricos e sociais sobre o trabalho e a sua importância para a formação do ser humano. Foram utilizados autores como Aranha (2010), Severino (2013), Pinto (2010), Carmo (2007), Saviani (2007), Manfredi (2009), Ianni (2004), entre outros. A estrutura do trabalho destaca em princípio o contexto de educação, ressaltando os conceitos e a aplicabilidade do referido termo. No segundo momento, o termo trabalho é contemplado, considerando a sua origem, bem como seus diversos percursos históricos. Finalizando, a proposta da pesquisa dimensiona a relação educação e trabalho no contexto das mais diversas aspirações no campo educacional.

Palavras-chave: Educação; trabalho; sociedade.

\section{Work and education}

\begin{abstract}
Producing an analysis about the theme of work and education, part of the need to detect, from the perspective of the specific literature, some strands that help in the process of understanding the elements that permeate and support the relation work and education. The objective of this analysis is to list specific questions that highlight the historical and social contexts about work and its importance for the formation of the human being. We used authors such as Aranha (2010), Severino (2013), Pinto (2010), Carmo (2007), Saviani (2007), Manfredi (2009) and Ianni (2004). The work structure highlights in principle the context of education, highlighting the concepts and applicability of the term. In the second moment, the term work is contemplated, considering its origin, as well as its diverse historical paths. Finally, the proposal of the research dimension the relation education and work in the context of the most diverse aspirations in the educational field.
\end{abstract}

Palavras-chave: Education; work; society.

\footnotetext{
${ }^{1}$ Professor de Ciências - Concursado da Secretaria de Educação de Juazeiro do Norte-CE; Engenheiro Agrônomo - Concursado da Secretaria de Meio Ambiente, Agricultura e Serviços Públicos - SEMASP/JN/CE - Espec. em Resíduos Sólidos/UFRN; Pós-Graduado em Recursos Hídricos/UFC; Mestrando em Educação - Anne Sullivan Univerity;

${ }_{2}^{2}$ Graduado em História pela Universidade Regional do Cariri - URCA, Especialista em História Moderna e Contemporânea pela Pontifícia Universidade Católica de Minas Gerais - PUC-MG, Mestre em História Social pela Universidade Federal do Rio de Janeiro - UFRJ, Doutor em História pelo Programa História, Ideologias e Culturas Políticas Contemporâneas da Universidade de Sevilla/Espanha. Professor Efetivo Adjunto da Universidade Regional do Cariri.
} 
Id on Line Revista Multidisciplinar e de Psicologia

Id on Line Multidisciplinary and Psycology Journal

\title{
Introdução
}

A relação que envolve três dos principais argumentos para a vida em sociedade (sociedade, trabalho e educação), dinamiza as práticas humanas no que diz respeito à produção de uma determinada cultura, imbuída de valores, de costumes, dos aspectos políticos, econômicos e religiosos.

Ao longo dos tempos, o ser humano vem desenvolvendo uma metodologia impregnada por buscas incansáveis, tanto no universo da sua produção material quanto nos fatores intelectuais, objetivando uma melhoria para sua convivência social, dentro de um modelo moderno, pautado nas inovações tecnológicas resultantes de um vasto processo de pesquisa. Buscas oriundas das necessidades sociais, através dos meios produtivos, das novas relações de trabalho e de um modelo educacional centralizado, às vezes tradicional, considerando-se o espaço e o tempo específicos; às vezes progressista.

O homem vive em sociedade. Não se reflete acerca de um tecido social sem considerar o conhecimento humano, nem muito menos as peculiaridades resultantes das suas ações produtivas tais como: a cultura, o trabalho e a educação.

Aguiar (2013), ao interpretar e analisar os aspectos sociais que dinamizam a sociedade do século XXI destaca que o movimento de transformação do mundo não se encerra em si mesmo. A política, a economia e as diferentes formas de organização social: família, escola e trabalho, se surpreendem pela velocidade com que produzem novas relações ou rearranjam suas antigas formas.

Segundo Aguiar (2013, p. 25)

\begin{abstract}
Apesar das dificuldades de interpretar um mundo em processo acelerado de mudanças em todas as esferas da vida social, os sociólogos têm apresentado diversas contribuições para a compreensão da sociedade que emerge no século XXI. Essas interpretações são construídas sobre as novas tecnologias de comunicação, as novas relações de trabalho, os novos arranjos políticos e de representação e sobre aspectos de sociabilidade, como a criminalidade e o consumismo.
\end{abstract}

O grifo na citação reflete a necessidade de se destacar o que Ianni (2004) verbaliza sobre a relação trabalho e sociedade. Para o autor, todas as inúmeras mudanças no mundo do trabalho são quantitativas e qualitativas, afetando a estrutura social nas mais diferentes escalas. Em meio a essas mudanças, verifica-se o rompimento dos quadros sociais ligados a um paradigma 
Id on Line Revista Multidisciplinar e de Psicologia

Id on Line Multidisciplinary and Psycology Journal

moderno, ou seja, com o trabalho flexível e volante no mundo todo, pessoas migram para outros países em busca de trabalho.

Como pressuposto para esse evento, a educação possibilita uma gama de base teórica subsidiada por práticas que promovem o conhecimento, necessário ao convívio social e aos aspectos econômicos, que dinamizam as relações entre os agentes sociais.

Pode-se definir a educação como sendo o meio pelo qual os seres humanos transmitem o conhecimento de uma geração a outra. Sendo, portanto, um fato eminentemente humano. Mas isso é pouco ao se considerar as transformações e mudanças entre as gerações. Logo, não se trata de simples transmissão.

As pessoas criam, constroem, modificam o entendimento acerca das coisas, interpretam a realidade de diferentes modos, intervindo de diversas maneiras. A educação é o conjunto dos processos e dos procedimentos que permitem a qualquer criança aceder progressivamente à cultura, pois o acesso à cultura é o que distingue o homem do animal.

Os seres humanos dependem profundamente da educação para a sobrevivência e evolução. Diferentemente dos outros animais, não possuem em seu código genético instrumentos que os permitam produzir sua existência. Tudo lhes é ensinado por meio da educação. Até o sorriso é um aprendizado. Sem a educação não sobreviveríamos. Nesse sentido, pode-se afirmar que o homem se faz por meio da educação.

Na História da Educação ocidental, mais especificamente na cultura greco-romana, o acesso à educação já nasce marcado pela desigualdade. A educação oferecida às crianças mostra claramente a distinção entre as classes (Aranha, 2010).

$\mathrm{Na}$ realidade, sempre encontraremos alguém ou algum grupo definindo qual a melhor educação, "para que" e "para quem". A educação também atua sobre a vida e o crescimento da sociedade, em dois sentidos:

No desenvolvimento de suas forças produtivas, formação dos profissionais; No desenvolvimento de valores culturais, podendo sofrer variações diante de valores sociais novos, estando, portanto, longe de afirmar a existência de uma educação universal (Aranha, 2010).

$\mathrm{Na}$ verdade, as pessoas preservam um tanto de si mesmas, de suas histórias e origens, que mesmo a educação formal, com todo seu aparato repressor, não consegue suprimir. O ser humano, ao mesmo tempo em que reproduz a cultura na sociedade, por meio da educação, também cria. É impossível controlá-lo integralmente (Aranha, 2010). 
Id on Line Revista Multidisciplinar e de Psicologia

Id on Line Multidisciplinary and Psycology Journal

As classes dominadas aprenderam a recriar a educação de diversas formas (comunidades de bairro, nas comemorações, festas tradicionais etc.) e propagá-la aos mais jovens, preservando e disseminando um saber alheio às convenções sociais, resistindo, embora muitas vezes de modo silencioso, à invasão de outro saber.

A esperança na educação se fundamenta em acreditar que o ato humano de educar existe tanto no trabalho pedagógico quanto no ato político, que se trava por outro tipo de escola, por outro tipo de mundo; a educação pode ser ao mesmo tempo, movimento e ordem, sistema e contestação. Há uma natureza humana universal que consiste na possibilidade de aprender. Exposto esse raciocínio, você é capaz de responder: "para que serve a educação?" "Para que aprender?”.

Nas sociedades primitivas, a educação familiar, essencial para a sobrevivência humana, dava conta de ensinar o que era importante e imprescindível para a preservação da espécie e o convívio no grupo. Esse modelo é denominado educação assistemática: nada planejada, mas coerente - aprendia-se a fazer fazendo, um aprendizado para a vida, que ocorria na rede de troca mais persistente e universal da sociedade humana: a família (Aranha, 2010).

É importante que você perceba que a educação pode ocorrer onde não há escola e por toda parte pode haver redes e estrutura sociais de transferência de saber de uma geração a outra. A evolução da cultura humana levou o homem a transmitir conhecimento, criando situações sociais de ensinar--aprender-ensinar.

Com a complexidade da sociedade, a educação deixa de se restringir apenas ao núcleo familiar, passando a ser realizada de modo mais planejado e intencional, por meio de preceptores contratados para educar as crianças e mais tarde pelas instituições, como a Igreja, e por fim as escolas, sendo que nestas os conteúdos das aprendizagens não se restringiam apenas às necessidades imediatas de sobrevivência, multiplicam-se em quantidade e profundidade. "Para que aprender" passa a ter outras implicações e intencionalidades.

Segundo Brandão (2009), a educação aparece sempre que surgem formas sociais de condução e controle da aventura de ensinar e aprender, e, quando ela se sujeita à Pedagogia, torna-se ensino formal, cria situações próprias para seu exercício e constitui executores especializados. É quando aparecem escolas, alunos e professores.

$\mathrm{Na}$ atualidade, verificam-se muitos discursos defendendo a educação como um meio imprescindível para tornar o ser humano melhor. Mas você precisa se perguntar: melhor em 
Id on Line Revista Multidisciplinar e de Psicologia

Id on Line Multidisciplinary and Psycology Journal

quê? Melhor para quê? Para quem? A educação não é neutra, está imersa no tecido social, cujos valores e conhecimentos procedem de uma sucessão de ocorrências existenciais, portanto, não são frutos de uma natureza humana estável. Por isso, o que se defende como importante ensinar e qual ser humano queremos formar variam de uma sociedade para outra, no tempo e no espaço. Contudo, uma coisa é fato: aprende-se a ser humano pela educação, o que consiste em desenvolver as potencialidades de cada um. Dizer que um ser humano é melhor ou pior que outro depende para qual sociedade (Aranha, 2010).

A educação é um meio pelo qual o homem desenvolve suas potencialidades biopsíquicas inatas, mas que não atingem a sua perfeição sem a aprendizagem realizada através da educação. Em qualquer tipo de sociedade, a educação é um meio de transmissão dos conhecimentos acumulados pela humanidade: a linguagem, o pensamento, as técnicas, as ciências, as artes, a moral, a religião, os valores, costumes, sentimentos, modos de expressá-los etc. O que difere são os conteúdos desses conhecimentos que assumem especificidades nas diferentes culturas. Se o conteúdo da educação é variável, a necessidade de ser educado é universal, porque ela é inerente ao homem. A natureza humana é o que exige ser educado; é também o que faz que a educação não seja tudo. Inversamente, se a educação não pode tudo, não se pode nada sem ela (Aranha, 2010).

Para Severino (2013), a relação entre educação e sociedade é muito íntima. O testemunho histórico das ciências do homem, no que concerne a educação informal, bem o mostra: as práticas informais da educação trazem implícita uma forma de se conceber a sociedade e revelam o tipo de sociedade onde elas acontecem.

Aranha (2010) esclarece que a organização social das diversas tribos, baseava-se em um tipo de estrutura promotora de uma específica homogeneização entre as relações sociais, sem sinais de dominação de um segmento sobre o outro. Mesmo considerando o fato de que a divisão de tarefas fosse realizada de forma diferente, ou seja, as pessoas exerciam funções distintas, evidenciando a prática de que o trabalho e o seu produto fossem sempre coletivos.

No campo da educação, as práticas eram desenvolvidas em meio às comunidades, priorizando a aprendizagem por imitação. As crianças aprendiam utilizando o método da imitação dos gestos dos adultos, tanto nas atividades diárias, quanto nos rituais. 
Id on Line Revista Multidisciplinar e de Psicologia

Id on Line Multidisciplinary and Psycology Journal

Nos mais diversos contextos históricos, a educação passa a ser vista e praticada nos moldes relacionados entre o informal e o formal. Este último refletindo a sistematização e consequentemente o método científico com intencionalidades e objetividades.

Diante desse quadro, a educação, sob a ótica da inserção social, passa a ser conceituada como uma prática social e histórica. Ocorre no universo de uma determinada sociedade, contemplando a dinâmica dos comportamentos sociais, costumes, instituições, atividades culturais e organizações burocrático-administrativas. A educação é um invento social que se desdobra no tempo histórico (Severino, 2013).

O processo educativo representa uma ferramenta insubstituível para o aspecto mediador que embasa a sociabilidade, proporcionando a compreensão de que o fator humanização, que personaliza o homem, atua no sentido de inserir novos sujeitos no universo social, evidenciando a ideia de que a sociedade encontra-se estruturada por meio de relações políticas que comprovam a existência de um modelo estratificado, hierarquizado e ideológico.

A educação passa a ser considerada como aparelho ideológico à medida que conserva e, em seguida, reproduz determinados conceitos e valores, transmitindo-os às novas gerações e perpetuando simultaneamente as relações sócias vigentes na sociedade. Por outro lado, percebese que a educação atua no sentido inverso à reprodução quando reage aos conteúdos ideológicos definidos e fomenta o estabelecimento de novas relações político-sociais com menor força de opressão.

Acerca do conceito de educação, Pinto (2010), destaca como sendo um processo pelo qual a sociedade forma seus membros à sua imagem e em função dos seus interesses. Acrescenta, ainda, características tais como: a educação é um processo; um fato existencial; um fato social; um fenômeno cultural; uma atividade teleológica; um fato de ordem consistente; um processo exponencial; concreta; contraditória e uma modalidade de trabalho social. Para compreendê-la é fundamental classificar os aspectos que definem o conceito de trabalho.

Ao se propor analisar o conceito de trabalho atrelado aos aspectos educacionais, importa explorar e destacar o que se considera por muitos como algo controverso, os meandros teóricos que embasam a origem deste que se denomina pela grande maioria como uma atividade produtiva.

Carmo (2007), em seu A ideologia do trabalho, destaca que a palavra trabalho vem do latim tripalium, nome de um instrumento formado por estacas, em uma quantidade de três, 
Id on Line Revista Multidisciplinar e de Psicologia

Id on Line Multidisciplinary and Psycology Journal

utilizado para manter presos bois ou cavalos difíceis de ferrar. No latim vulgar, passa a significar pena ou servidão do homem à natureza.

Todavia, com a necessidade de sobrevivência por parte dos homens e o seu contato direto com a natureza através da exploração de bens naturais, surge a modernização das novas técnicas produtivas e, concomitantemente, a necessidade de um modelo de trabalhador mais centralizado nas características intelectuais.

No campo das relações produtivas do ser humano, a educação representa uma ação exclusiva do homem, ou seja, ela se caracteriza como elemento norteador e condutor dos diversos segmentos do processo de socialização e consequentemente da sociabilidade.

Ao relacionar educação e trabalho, Saviani (2007) evidencia que ambas são atividades especificamente humanas. Em síntese, o ser humano trabalha e educa.

Ao propor uma análise sobre se realmente o homem promove educação e trabalho, Saviani (2007, p.08) esclarece:

Pressupõe-se (...) uma definição de homem que indique em que ele consiste; isto é, sua característica essencial a partir da qual se possa explicar o trabalho e a educação como atributos do homem. E nesse caso, fica aberta a possibilidade de que trabalho e educação sejam considerados atributos essenciais do homem.

Historicamente percebe-se um conjunto significativo de práticas voltadas para o entendimento da relação trabalho e educação. Verifica-se que, já na primeira metade do século XVIII, a Companhia de Jesus disponibilizou oficinas nas quais os denominados mestres jesuítas repassavam os conhecimentos básicos acerca dos ofícios mais necessários.

Manfredi (2009) preconiza que, após o desenvolvimento da economia, bem como com a intensificação do processo urbanizatório, verificou-se um aumento na demanda de artesãos. Para a autora, várias lojas de ofício foram criadas, obedecendo, dentro de um critério definido pela presença de corporações existentes em Portugal. Assim, os mestres registravam os aprendizes que, após um período de quatro anos, eram contemplados com certificados.

Outro aspecto fundamental na análise sobre educação e trabalho, faz referência ao que se pode esperar das chamadas novas gerações. É fato que, no Brasil, um jovem iniciava suas práticas produtivas muito cedo, na maioria das vezes em atividades que exigiam pouco ou quase 
nenhuma formação escolar. A partir da democratização da educação, a entrada para o mercado de trabalho ocorre em tempos posteriores.

Sobre essa mudança, Carmo (2007, p. 121) destaca:

As transformações do trabalho urbano industrial liberam crianças e adolescentes da participação da produção direta e, em decorrência, a procura pela escola básica pública aumenta. Ocorreu no Brasil uma rápida valorização e universalização da escolaridade dos jovens das camadas populares.

Entretanto, verifica-se outro fator que não condiz com as propostas de melhoria e de adequação no universo educação-trabalho: a realidade que sobrepuja os anseios de uma vida melhor. Sobre este ponto, Carmo (2007, p. 121) ressalta:

Para uma (...) camada de jovens, a escola e o saber por ela difundido têm pouco valor em si, e a situação se agrava para as novas gerações que vêm se dando conta do fraco impacto da escolaridade na vida da geração de seus pais (...). É comum encontrar jovens que abandonam prematuramente a escola com a justificativa de procurar emprego.

As condições acima especificadas ratificam o fato de que a educação reflete o modelo social predominante nas relações entre os homens e que, se a educação contribui de uma forma efetiva para o processo reprodutivo e sistematizado de uma determinada ideologia, ao mesmo tempo pode ser uma proposta de transformação social por intermédio de uma posição contrária à ordem estabelecida.

\section{Considerações Finais}

O tema desenvolvido neste trabalho estimulou a necessidade de um novo olhar sobre os conceitos e as aplicabilidades dos termos sociedade, educação e trabalho. Os diversos autores utilizados para embasarem os argumentos propostos, dentro das suas perspectivas, contribuíram de uma forma ímpar para que se chegasse aos objetivos sinalizados anteriormente (resumo). Importa destacar e ratificar a relevância deste estudo para futuras pesquisas. 
Id on Line Revista Multidisciplinar e de Psicoloqia

Id on Line Multidisciplinary and Psycology Journal

\section{Referências}

AGUIAR, João Catrânio. Sociologia em desenvolvimento. São Paulo: Moderna, 2013.

ARANHA, Maria Lucia de Arruda. História da educação e da pedagogia geral e do Brasil. São Paulo: Moderna, 2010.

CARMO, Paulo Sérgio do. A ideologia do trabalho. São Paulo: Moderna, 2007.

IANNI, Otávio. O mundo do trabalho. São Paulo: Sead, 2004.

MANFREDI, Silvia Maria. Educação profissional no Brasil. São Paulo: Cortez, 2009.

PINTO, Álvaro Vieira. Sete lições sobre educação de adultos. São Paulo: Cortez, 2010.

SAVIANI, Dermeval. Trabalho e educação: fundamentos ontológicos e históricos. São Paulo: Unicamp, 2007.

SEVERINO, Antônio Joaquim. Filosofia da educação. São Paulo: FTD, 2013.

Como citar este artigo (Formato ABNT):

SAMPAIO, A.P.S.; ANDRADE, I.L. Trabalho e Educação . Id on Line Revista Multidisciplinar e de Psicologia, Nov-Dez. de 2016, vol.10, n.32, p. 138-146. ISSN: 1981-1179.

Recebido: $14 / 09 / 2016$

Aceito: $24 / 10 / 2016$ 